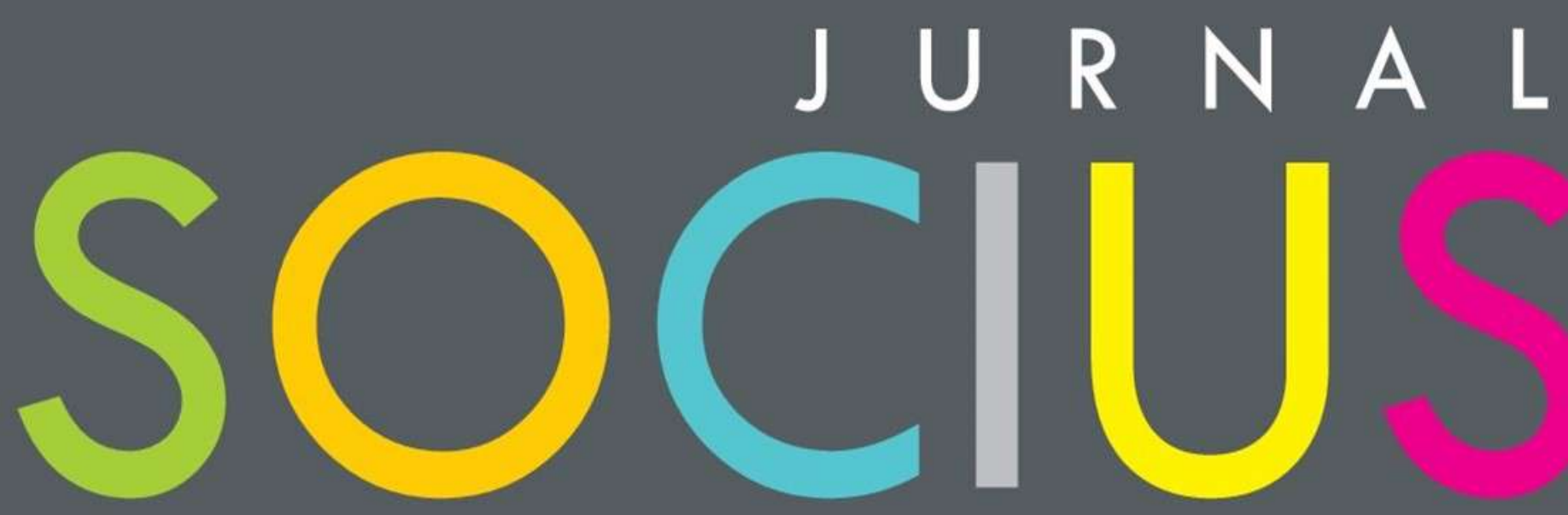

Journal of Sociology Research and Education

DITERBITKAN OLEH :

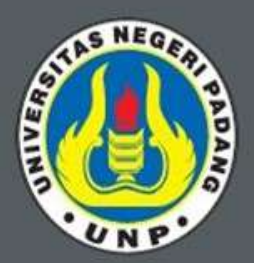

LABOR

JURUSAN SOSIOLOGI

FAKULTAS ILMU SOSIAL

UNIVERSITAS NEGERI PADANG

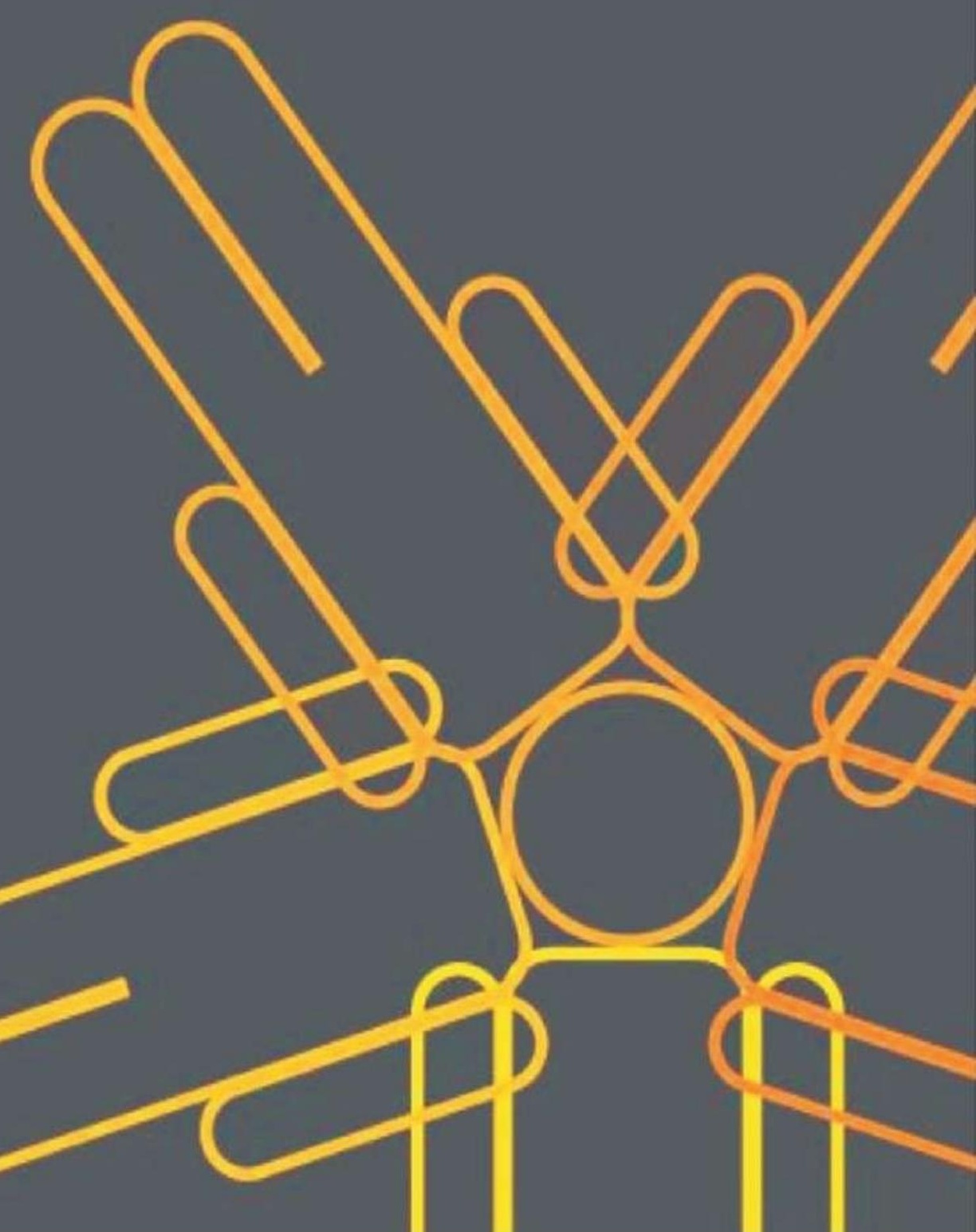




\section{SOCIUS}

Vol. 8, No. 1, Th. 2021

ISSN : 2356-4180 (cetak)

2442-8663 (online)

\begin{tabular}{|c|c|}
\hline $\begin{array}{c}\text { REDAKSI } \\
\text { JURNAL SOCIUS }\end{array}$ & DAFTAR ISI \\
\hline $\begin{array}{l}\text { Editor in Chief : } \\
\text { Desy Mardhiah } \\
\text { (Universitas Negeri Padang) }\end{array}$ & $\begin{array}{c}\text { Arni Darmayanti, Gede Budarsa } \\
\text { Peran Ganda Perempuan Bali di Masa Pandemi Covid-19 } \\
\text { Halaman 1-12 }\end{array}$ \\
\hline $\begin{array}{l}\text { Managing Editor : } \\
\text { Erda Fitriani } \\
\text { (Universitas Negeri Padang) }\end{array}$ & $\begin{array}{c}\text { Luthfi Hasanal Bolqiah, Riaty Raffiuddin } \\
\text { Dominasi Oligarki dalam Pembangunan Reklamasi Pantai Utara Jakarta } \\
\text { Halaman 13-25 }\end{array}$ \\
\hline $\begin{array}{l}\text { Editorial Board: } \\
\text { Elfitra Baikoeni } \\
\text { (Universitas Andalas) }\end{array}$ & $\begin{array}{c}\text { Rinel Fitlayeni, Ikhsan Muharma Putra, Marleni Marleni, } \\
\text { Elvawati Elvawati, Winda Sri Yulia Putri }\end{array}$ \\
\hline $\begin{array}{c}\text { Iskandar } \\
\text { (Universitas Trunojoyo) }\end{array}$ & $\begin{array}{c}\text { Penguatan Kapasitas Pedagang dalam Resolusi Konflik Asimetris di } \\
\text { Pasar Raya Padang Pasca Gempa }\end{array}$ \\
\hline $\begin{array}{c}\text { Ike Sylvia } \\
\text { (Universitas Negeri Padang) }\end{array}$ & Halaman 26-35 \\
\hline $\begin{array}{c}\text { Erianjoni } \\
\text { (Universitas Negeri Padang) } \\
\text { Emizal Amri } \\
\text { (Universitas Negeri Padang) }\end{array}$ & $\begin{array}{c}\text { Dahlia Morina Hutagalung, Ferdinand Kerebungu, Maryam } \\
\text { Lamadirisi } \\
\text { Perilaku Belajar Mahasiswa Batak Toba di Universitas Negeri Manado } \\
\text { Halaman 36-46 }\end{array}$ \\
\hline $\begin{array}{l}\text { Mohammad Isa Gautama } \\
\text { (Universitas Negeri Padang) }\end{array}$ & $\begin{array}{c}\text { Rifqi Asy'ari, Rusdin Tahir, Cecep Ucu Rakhman, Rifki } \\
\text { Rahmanda Putra }\end{array}$ \\
\hline $\begin{array}{l}\text { Khairul Fahmi } \\
\text { (Universitas Negeri Padang) }\end{array}$ & $\begin{array}{l}\text { Pengembangan Pariwisata Berbasis Masyarakat di Provinsi Jawa Barat } \\
\text { Halaman 47-58 }\end{array}$ \\
\hline $\begin{array}{c}\text { Reno Fernandes } \\
\text { (Universitas Negeri Padang) }\end{array}$ & $\begin{array}{c}\text { Reno Fernandes, Azwar Ananda, Maria Montessori, Firman } \\
\text { Firman, Eka Vidya Putra, Hendra Naldi, Erda Fitriani }\end{array}$ \\
\hline $\begin{array}{c}\text { Layout Editor: } \\
\text { Rhavy Ferdyan } \\
\text { Technical Support: } \\
\text { Rudi Mahesa }\end{array}$ & $\begin{array}{c}\text { Adaptasi Dosen Digital Immigrant Terhadap Pelaksanaan Pembelajaran } \\
\text { pada Masa Pandemi Covid-19 } \\
\text { Halaman 59-72 }\end{array}$ \\
\hline $\begin{array}{c}\text { Alamat Redaksi: } \\
\text { Jurusan Sosiologi FIS UNP } \\
\text { Jl. Prof.Dr.Hamka } \\
\text { Kampus UNP Air Tawar } \\
\text { e-mail: socius@ppj.unp.ac.id }\end{array}$ & \\
\hline $\begin{array}{l}\text { Penerbit } \\
\text { Labor Jurusan Sosiologi } \\
\text { Universitas Negeri Padang }\end{array}$ & \\
\hline
\end{tabular}




\title{
Adaptasi Dosen Digital Immigrant Terhadap Pelaksanaan Pembelajaran pada Masa Pandemi Covid-19
}

\author{
Reno Fernandes ${ }^{1}$, Azwar Ananda $^{2}$, Maria Montessori ${ }^{3}$, Firman Firman ${ }^{4}$, Eka Vidya Putra ${ }^{5}$, \\ Hendra Naldi ${ }^{6}$, Erda Fitriani ${ }^{7}$ \\ 1,2,3,4,5,6,7 Universitas Negeri Padang \\ Email: renofernandes@ fis.unp.ac.id
}

\begin{abstract}
Abstrak
Penelitian ini bertujuan untuk menjelaskan bagaimana adaptasi pembelajaran melalui E-learning yang dilakukan oleh dosen digital immigrant di Universitas Negeri Padang (UNP). Hal ini menarik untuk dikaji, karena pada masa Pendemi Covid-19 telah mengubah sistem pelaksanaan perkuliahan di UNP dari tatap muka langsung menjadi tatap maya dengan memanfaatkan E-Learning yang tentunya bertumpu kepada penguasaan teknologi. Sementara itu ada sekelompok dosen yang lemah dalam penguasaan teknologi informasi, namun tetap harus mampu beradaptasi dengan kondisi saat ini agar proses perkuliahan tetap berjalan. Kelompok ini kemudian dikenal dengan istilah digital immigrant. Proses adaptasi dalam pelaksanaan pembelajaran yang dilakukan oleh dosen digital immigrant ini akan dianalisis dengan menggunakan teori struktural fungsional dari Talcott Parsons. Penelitian ini menggunakan metode campuran, kuantitatif dan kualitatif. Hasil penelitian menunjukkan dosen digital immigrant memiliki keterbatasan dalam melaksanakan pembelajaran menggunakan platform E-Learning UNP. Bagi dosen digital immigrant sistem E-Learning UNP tersebut platform pembelajaran formal yang tidak sederhana dan tidak praktis digunakan. Namun dalam perjalanannya dosen digital immigrant tetap beradaptasi dengan cara terus belajar, sembari melaksanakan pembelajaran secara sinkronus menggunakan aplikasi digital lainnya seperti WhatsApp dan aplikasi video conference (Google Meet dan Zoom Meeting). Sementara untuk pemeliharaan pola sistem pembelajaran di E-learning UNP dosen digital immigrant meminta bantuan kepada sejawat dosen muda untuk menginputkan konten-konten tersebut ke dalam ELearning. Namun secara prinsip, berbagai kebutuhan pelaksanaan pembelajaran seperti rencana pembelajaran semester, bahan ajar, media pembelajaran, soal ujian, bahan tugas tetap disediakan oleh dosen digital immigrant. Hal ini dilakukannya untuk pencapaian tujuan pembelajaran tetap berlangsung di masa pandemi Covid-19.
\end{abstract}

Kata kunci: Adaptasi, Covid-19, Dosen, Digital immigrant, E-Learning

\begin{abstract}
This study aims to explain how learning adaptation through E-learning is carried out by digital immigrant lecturers at Universitas Negeri Padang (UNP). This is interesting to study, because during the Covid-19 Pandemic, the system for implementing lectures at UNP from face-to-face to virtual face-to-face by utilizing E-Learning which of course relies on mastery of technology. Meanwhile, there is a group of lecturers who are weak in mastering information technology, but still have to be able to adapt to current conditions so that the lecture process continues. This group came to be known as digital immigrants. The adaptation process in the implementation of learning carried out by digital immigrant lecturers will be analyzed using structural functional theory from Talcott Parsons. This research uses mixed methods, quantitative and qualitative. The results of the study show that digital immigrant lecturers have limitations in carrying out learning using the UNP ELearning platform. For digital immigrant lecturers, the UNP E-Learning system is a formal learning platform that is neither simple nor practical to use. However, on the way, digital immigrant lecturers continue to adapt by continuing to learn, while carrying out synchronous learning using other digital applications such as WhatsApp and video conference applications (Google Meet and Zoom Meeting). Meanwhile, for the maintenance of the learning system pattern at UNP's E-learning, digital immigrant lecturers asked for assistance from their fellow young lecturers to input these
\end{abstract}


contents into E-Learning. However, in principle, various learning implementation needs such as semester learning plans, teaching materials, learning media, exam questions, assignment materials are still provided by digital immigrant lecturers. This is done to achieve the learning objectives that will continue during the Covid-19 pandemic.

Keyword: Adaptation, Covid-19, Digital immigrant, E-Learning, Lecturer

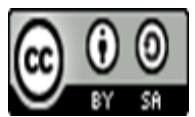

Received: February 22, 2020

Revised: June 29, 2021

Available Online: June 30, 2021

\section{Pendahuluan}

Pandemi Covid-19 mendatangkan masalah baru sebagian besar negara di dunia. Krisis kesehatan ini menjadi akar terjadinya masalah pada institusi sosial salah satunya pada institusi pendidikan. Akibat wabah Covid-19, negara maju hingga negara dunia ketiga mengambil langkah social distancing yang berujung pada penutupan sekolah pada tingkat dasar hingga perguruan tinggi. Menurut Viner (2020) penutupan sekolah diberbagai belahan negara didunia dinilai sangat efektif mengurangi laju perkembangan penyebaran Covid-19. Namun pada sisi lain agenda penutupan sekolah tersebut juga diprediksi akan mempengaruhi keberlangsungan institusi pendidikan.

Pandemi Covid-19 juga berdampak pada berubahnya pelaksanaan pembelajaran di perguruan tinggi, yang sebelumnya proses pembelajaran dilaksanakan melalui tatap muka berubah menjadi pembelajaran online (daring). Menurut press release yang dikeluarkan oleh UNESCO proses pembelajaran ini berjalan tidak efektif, karena berbagai kendala. Kendala utama dialami oleh peserta didik itu sendiri. Data menunjukkan bahwa 826 juta siswa tidak komputer untuk menunjang proses pembelajaran dan sementara 706 juta siswa tidak memiliki internet di rumah untuk menunjang pembelajaran jarak jauh berbasis digital, sehingga membuat kondisi belajar menjadi tidak efektif. Keadaan ini diperparah dengan minimnya kecapakan pendidik di negara berkembang terhadap penguasaan teknologi informasi dan komunikasi yang dapat digunakan untuk kepentingan pembelajaran. (UNESCO, 2020). Hal yang sama juga terjadi di Indonesia. Pada awal pandemi, Indonesia juga menetapkan kebijakan penutupan aktivitas pembelajaran di sekolah dan di kampus serta mengalihkan pembelajaran dengan sistem online. Penutupan pembelajaran tersebut mengacu kepada kebijakan menteri pendidikan kebudayaan Nomor 36962/MPK.A/HK/2020 tentang pembelajaran secara daring dan bekerja dari rumah dalam rangka pencegahan penyebaran virus Covid-19, yang ditanda tangani pada tanggal 17 maret 2020.

Kebijakan pembelajaran secara online dalam institusi pendidikan di Indonesia sebenarnya bukanlah sesuatu yang baru, karena pembelajaran online diberbagai perguruan tinggi selama ini telah dikembangkan, sehingga para pendidik juga memiliki kesempatan untuk meninjau kembali asumsi mendasar tentang bagaimana mereka mengajar dan bagaimana siswa belajar (Rusli, Rahman, \& Abdullah, 2020). Tuntutan kepada dosen selama ini adalah bagaimana dapat mengikuti perubahan teknologi, teori belajar dan perubahan kebutuhan pendidikan peserta didik yang notabene adalah kelompok pelajar digital native (Ghaith, 2010). Hal ini karena pengembangan pembelajaran secara online ini akan bertumpu kepada sumber daya manusia yaitu tenaga pengajar yang mampu mengoperasionalkan berbagai teknologi yang dibutuhkan oleh pembelajaran daring (Komariah, Kurniady, \& Rusdinal, 2019). Namun disisi lain masalah pembelajaran pada abad 21 terletak pada generasi pengajar yang lahir sebelum tahun 1980 yang disebut sebagai digital immigrant. Mereka memiliki kemampuan yang berbeda dengan kebutuhan generasi yang lahir pada era digital yang disebut dengan digital native (Prensky, 2001b). Perbedaan ini terdapat pada karakteristik keterampilan penguasaan 
dan pemanfaatan teknologi informasi. Digital immigrant juga dipandang memiliki ketergantungan yang berlebihan pada metodologi pengajaran yang lama yang dalam hal ini diartikan mengajar dengan mengunakan metode ceramah tanpa pengunaan teknologi (Koumachi, 2019). Menurut Riegel \& Mete (2017), selama ini digital immigrant lebih suka mengajar dengan proses interaksi langsung dari pada interaksi digital. Dosen yang termasuk pada kelompok ini lebih suka mendiskusikan pekerjaan rumah harian secara langsung dari pada mempostingnya di situs web dan meminta siswa mengonfirmasi secara elektronik ketika sudah selesai.

Ada banyak penelitian yang menyatakan bahwa generasi digital immigrant sebagai pengajar tidak bisa beradaptasi dengan pola pembelajaran yang dituntut dalam pembelajaran abad 21. Karekteristik digital immigrant dalam pembelajaran lebih suka interaksi langsung dari pada interaksi digital. Menurut mereka dalam proses pembelajaran seorang pendidik dapat mengevaluasi pembelajaran melalui komunikasi nonverbal (Bahasa tubuh, nada suara, ekspresi wajah) (Riegel \& Mete, 2017). Digital immigrant lebih melihat teknologi hanya sebagai tambahan memperlancar proses pembelajaran seperti menggunakan video sebagai alat bantu untuk menjelaskan pembelajaran, namun tidak mengganggap mengajar dengan virtual sebagai proses pembelajaran. Digital immigrant dipandang terlalu sulit untuk mempelajari teknologi baru dan juga sudah terlambat bagi mereka untuk belajar tentang perangkat elektronik baru, program pendidikan elektronik, dan aplikasi (Reid \& Ostashewski, 2011).

Universitas Negeri Padang (UNP) merupakan salah satu perguruan tinggi di Indonesia yang melaksanakan pembelajaran secara daring melalui E-Learning. Pandemi Covid-19 yang terjadi di Indonesia membawa dampak kepada kebijakan di Universitas Negeri Padang. Terhitung tanggal 14 maret 2020 Rektor Universitas Negeri Padang mengeluarkan surat keputusan tentang pelaksanaan perkuliahan secara daring melalui platform E-Learning UNP. Kondisi ini tentunya membawa sesuatu yang dilematis. Pada satu sisi pembelajaran E-Learning belum optimal dilaksanakan dan akselerasi dari dosen juga masih teramat terbatas. Sementara pada sisi lain dalam kondisi pandemi Covid-19 pembelajaran menggunakan E-Learning merupakan sebuah keharusan.

Di Universitas Negeri Padang pembelajaran menggunakan E-Learning bukanlah sesuatu yang baru. Universitas Negeri Padang (UNP) sejak tahun 2010 telah melengkapi sistem pembelajaran dengan fasilitas E-Learning berbasis Moodle (Modular Object, Oriented Dynamic Learning). Di UNP pembelajaran menggunakan E-Learning dapat dilaksanakan maksimal $50 \%$ dari total 16 kali pertemuan. Penggunaan E-Learning bertujuan untuk meningkatkan mutu pembelajaran, membangun budaya student center learning dan mengubah kebiasaan dan budaya belajar menjadi independent learning (Bentri \& Rahmi, 2016). Secara khusus manfaat E-Learning bagi dosen idealnya dapat mengubah gaya mengajar yang berdampak pada profesionalitas kerja, memberi peluang menilai siswa dan mengevaluasi pembelajaran setiap siswa dan mengeksplorasi diri secara efisien (Khairudin, Rahmi, Rahmidani, Rusdinal, \& Gistituati, 2019).

Berdasarkan penelusuran dokumen yang dilakukan melalui Website www.sie.unp.ac.id tercatat hingga tahun 2020, UNP memiliki 1221 orang dosen. Jika kita kelompokkan berdasarkan pendapat Prensky, bahwa mereka yang lahir sebelum tahun 1980 dikategorikan sebagai digital immigrant, sementara kelahiran setelah tahun 1980an dikategorikan sebagai digital native. Maka dosen UNP yang dapat disebut digital immigrant berjumlah 725 orang atau setara dengan $59.3 \%$ sementara dosen digital native hanya 496 orang atau 40,6 \%. Data ini mendukung pentingnya penelitian tentang kelompok dosen digital immigrant, terutama berkaitan dengan adaptasi dosen digital immigrant terhadap pembelajaran menggunakan ELearning. Tujuan penelitian ini adalah untuk menjelaskan bagaimana proses adaptasi yang dilakukan oleh dosen digital immigrant dalam menyikapi pembelajaran menggunakan sistem E-Learning di UNP. Penelitian ini penting dilakukan mengingat di UNP jumlah dosen digital 
immigrant lebih banyak dibanding jumlah dosen digital native, namun mereka mampu beradaptasi dengan tuntutan pembelajaran daring dengan segala keterbatasan yang mereka miliki terutama dalam hal penguasaan teknologi.

Penelitian serupa terkait dengan pembelajaran daring dengan penggunaan E-Learning telah dilakukan oleh beberapa peneliti sebelumnya. Andrizal \& Arif (2017) menemukan bahwa penggunaan E-Learning di UNP belum terlaksana secara optimal. Salah satu penyebabnya adalah minimnya pengetahuan dan keterampilan dosen dalam memanfaatkan E-Learning untuk kepentingan pembelajaran. Pemanfaatan E-Learning di Universitas Negeri Padang juga terkendala dalam hal kemampuan dosen dalam menggunakan teknologi informasi. Selain itu Rahmat \& Ridwan (2020) menemukan fakta bahwa banyak dosen senior merasa pembelajaran menggunakan E-Learning bukan sebuah proses pembelajaran, namun hanya dipahami sebagai media pembelajaran

Meskipun penelitian di atas telah membahas tentang pelaksanaan pembelajaran ELearning, namun sebatas evaluasi pembelajaran menggunakan E-Learning. Sementara itu penelitian ini membahas hal yang lebih mendalam terkait proses adaptasi yang dilakukan oleh dosen digital immigrant, agar dapat melaksanakan pembelajaran kepada mahasiswa dengan menggunakan teknologi digital, sementara pada sisi lain para dosen memiliki keterbatasan dalam menggunakan teknologi tersebut. Dengan demikian tulisan ini memiliki kebaruan yang belum pernah dibahas oleh peneliti sebelumnya. Penelitian ini semakin menarik karena temuan penelitian dianalisis menggunakan Teori Struktural Fungsional yang dikemukakan oleh Talcott Parsons, yang mempertajam pembahasan hasil penelitian, bukan hanya dari perspektif ilmu pendidikan tapi juga berdasarkan perspektif sosiologis.

\section{Metode Penelitian}

Penelitian ini menggunakan desain penelitian campuran. Metode kuantitatif dilakukan untuk mendapatkan data tentang pelaksanaan pembelajaran daring. Aplikasi pembelajaran yang digunakan serta kemampuan menggunakan E-Learning dalam pembelajaran di Universitas Negeri Padang. Penarikan sampel penelitian secara kuantitatif diambil dari 725 orang populasi dosen yang dikategorikan dosen digital immigrant yang telah dikelompokkan berdasarkan tahun kelahiran sebelum 1980. Jumlah sample dalam penelitian ini sebanyak 85 orang dengan confidence level $95 \%$ dan margin eror $10 \%$. Sementara agar penelitian ini lebih dalam tentang adaptasi dosen digital immigrant dalam melaksanakan pembelajaran daring peneliti menggunakan metode kualitatif dengan observasi dan wawancara secara mendalam sebanyak 10 orang dosen digital immigrant yang dipilih secara purposive sampling (Creswell, 2013).

\section{Hasil dan Pembahasan}

\section{Karakteristik Dosen Digital Immigrant}

Konsep generasi digital native dan digital immigrant pertama kali dimunculkan oleh Prensky (2001a). Lebih lanjut penelitian Li (2020) mengungkapkan dua ambang batas yang mendefinisikan generasi digital yaitu usia dan aksesibilitas. Literatur yang menyatakan bahwa usia menjadi landasan pengelompokan digital native dan digital immigran dikemukan oleh Prensky (2001a), O’Bannon \& Thomas (2014); Bowe \& Wohn (2015). Pendapat itu juga diperkuat oleh Helsper \& Eynon (2010) yang membahas mengenai kesenjangan generasi digital yang mengidentifikasi dua kelompok demografi berdasarkan kemampuan dalam menguasai teknologi.

Penduduk asli digital adalah orang yang lahir setelah tahun 1980, tumbuh tenggelam dalam teknologi, dan dengan demikian memiliki kemampuan tingkat tinggi untuk 
menggunakan teknologi; dan para immigrant digital adalah mereka yang lahir sebelum tahun 1980, tumbuh tanpa teknologi informasi dan komunikasi modern dan sebagai akibatnya kurang pengalaman dan atau kemampuan untuk menggunakan teknologi. Lebih lanjut pengkategorian antara digital native dengan digital immigran diungkapkan oleh Ransdell (2011) bahwa bahwa pengelompokan ini dapat dilihat dari 4 kategori generasi diantaranya: milenium, lahir pada 1982+; generasi X, lahir 1982-1971; boomer muda, 1972-1961; dan boomer yang lebih tua, 1962-1951. Generasi milenial lebih cenderung disebut dengan digital native dan generasi sebelumnya disebut sebagai digital immigrant.

Di sisi lain, penelitian Thinyane (2010), Kennedy (2008) membantah pendapat yang menyatakan usia menjadi pembeda dalam penguasaan teknologi. Menurutnya aksesbilitas untuk memiliki peralatan teknologi lebih menentukan seseorang dikatakan sebagai digital native atau immigrant. Maksudanya meskipun seseorang dilahirkan setelah tahun 1980 namun belum pernah menggunakan teknologi sampai dewasa mereka tidak bisa disebut sebagai digital native. Penelitian lain yang mendukung pernyataan di atas menyatakan status sosial ekonomi, tingkat pembangunan daerah (Helsper \& Eynon, 2010), dan pengalaman diri terhadap penggunaan komputer (Teo, 2016), merupakan indikator menentukan perbedaan generasi digital.

Meskipun terjadi perdebataan mengenai indikator digital native dan immigrant. Namun dalam penguasaan teknologi memang terjadi kesenjangan. Dalam institusi pendidikan Prensky (2001b) mengelompokkan perbedaan kemampuan antara pendidik dengan naradidik. Pendidik dipandang sebagai kelompok digital immigrant yang harus banyak menyesuaikan diri dengan naradidik generasi digital native. Salajan (2010) menyatakan bahwa terdapat perbedaan cara pandang antar generasi dalam memanfaatkan tekologi informasi dalam belajar dan mengajar. Sebagai contoh dosen digital immigrant akan menganggap mahasiswa yang menggunakan handphone dikelas sebagai bentuk penyimpangan terhadap aktivitas pembelajaran. Pendapat sama juga dikemukan oleh Thomas \& O'Bannon (2015), penelitiannya mengungkapkan generasi digital immigrant lebih senang memanfaatkan teknologi informasi sebagai alat bantu yang menyenangkan dalam pembelajaran.

Karakteristik digital immigrant dalam pembelajaran lebih suka interaksi langsung dari pada interaksi digital. Menurut mereka dalam proses pembelajaran seorang pendidik dapat mengevaluasi pembelajaran melalui komunikasi nonverbal (Bahasa tubuh, nada suara, ekspresi wajah) (Riegel \& Mete, 2017). Penelitian Kinash \& Wood (2013) mengungkapkan bahwa digital immigrant lebih melihat teknologi hanya sebagai tambahan memperlancar proses pembelajaran seperti menggunakan video sebagai alat bantu untuk menjelaskan pembelajaran, namun tidak mengganggap mengajar dengan virtual sebagai proses pembelajaran. Digital immigrant dipandang terlalu sulit untuk mempelajari teknologi baru dan juga sudah terlambat bagi mereka untuk belajar tentang perangkat elektronik baru, program pendidikan elektronik, dan aplikasi (Reid \& Ostashewski, 2011). Meskipun demikian Ransdell (2011) mengemukakan bahwa meskipun guru immigrant digital kurang percaya diri dalam penggunaan teknologi, mereka mampu menerapkan apa yang mereka pelajari tentang teknologi lebih baik daripada penduduk asli digital. Selama para guru imigran digital memiliki waktu dan aksesibilitas yang cukup, mereka dapat mempelajari teknologi untuk menjadi penduduk asli digital yang sebenarnya.

\section{E- Learning sebagai Bentuk Pola Pembelajaran Baru pada Masa Pandemi Covid-19}

Electronic Learning (E-Learning) adalah pembelajaran jarak jauh (distance learning) yang memanfaatkan teknologi komputer, jaringan komputer dan atau Internet (Mayes \& De Freitas, 2007). E-Learning memungkinkan mahasiswa untuk belajar melalui komputer di tempat mereka masing-masing tanpa harus secara fisik pergi mengikuti perkuliahan di kelas. 
E-Learning sering pula dipahami sebagai suatu bentuk pembelajaran berbasis web yang bisa diakses dari internet (Horton, 2011).

Universitas Negeri Padang merupakan salah satu perguruan tinggi di Indonesia yang telah menggunakan sistem pembelajaran dengan E-Learning. Sistem E-Learning yang digunakan oleh Universitas Negeri Padang berbasis Moodle (Modular Object Oriented Dynamic Learning). Beberapa fitur E-Learning yang dapat dimanfaatkan diantaranya adalah: Pengajuan tugas (Assignment Submission), Forum Diskusi, Upload (unggah) File, Download (unduh) File, Kuis Online, Penilaian (Grading), Bank soal, Pesan Instant Moodle, Kalender Online, Berita dan Pengumuman Online (Tingkat Program Kursus/ Kuliah dan Lembaga Pengelola), dan Wiki. Pembelajaran dengan e-learning di Universitas Negeri Padang dipadukan dengan pembelajaran tatap muka langsung atau Blended Learning. Pembelajaran dilaksanakan dengan 50\% menggunakan e-learning dan 50\% lainnya dilaksanakan dengan tatap muka langsung (Bentri \& Rahmi, 2016). Pelaksanaan pembelajaran dengan sistem ELearning di Universitas Negeri Padang telah berjalan semenjak tahun 2010.

Mengenai pelaksanaannya berbagai temuan penelitian menyatakan pemanfaatan ELearning untuk kepentingan pembelajaran selama ini masih mendapat berbagai kendala. Temuan penelitian Andrizal \& Arif (2017) menyebutkan penggunaan E-Learning di UNP belum terlaksana dengan baik yang diakibatkan oleh minimnya pengetahuan dan keterampilan dosen dalam memanfaatkan teknologi informasi khususnya menggunakan E-Learning untuk kepentingan pembelajaran. Pemanfaatan E-Learning di Universitas Negeri Padang. Temuan penelitian Rahmat \& Ridwan (2020) juga mengatakan pemanfaatan E- Learning untuk kepentingan pembelajaran terkendala oleh penolakan secara tidak langsung oleh dosen. Beberapa dosen senior di UNP pembelajaran dengan E-Learning bukanlah pembelajaran ideal, pembelajaran menggunakan sistem E-Learning dianggap akan mempersulit dosen dan mahasiswa mendapatkan hasil belajar dan capaian pembelajaran yang optimal. Keadaan ini membuat pemanfaatan pembelajaran menggunakan E-Learning belum bisa terlaksana sesuai rencana. Banyak dosen memilih untuk tetap mengajar secara tatap muka langsung di kelas.

Pandemi Covid-19 mengakibatkan berubah nya sistem pembelajaran di Perguruan Tinggi di Indonesia. Perkuliahan yang sebelumnya dilaksanakan secara tatap muka langsung atau sistem kelas. Harus dirubah secara drastis harus dilaksanakan dengan bantuan teknologi informasi atau biasa disebut dengan pembelajaran daring (dalam jaringan). Universitas Negeri Padang sebagai perguruan tinggi negeri secara langsung merespon perubahan tersebut. Rektor Universitas Negeri Padang telah mengeluarkan surat pada tanggal 14 maret 2020 tentang pelaksanaan perkuliahan secara daring melalui platform E-Learning UNP. Dalam surat yang ditandatangani oleh Rektor Universitas Negeri Padang secara tegas menyatakan bahwa perkuliahan di Universitas Negeri Padang harus tetap dilaksanakan secara terencana, sistematis dan terukur memalui E-Learning UNP.

Selain itu berdasarkan surat edaran Rektor UNP Pembelajaran pada masa pandemi menggunakan E-Learning dapat dilaksanakan melalui dua jalur yaitu dengan sinkronus yaitu interaksi pembelajaran antara dosen dan mahasiswa dilakukan pada waktu yang bersamaan, menggunakan teknologi video conference atau chatting. Pilihan dalam pembelajaran daring lainnya adalah asinkronus jalur ini dilakukan dengan cara dosen dapat menyiapkan materi lebih dulu, dan interaksi pembelajaran dilakukan secara fleksibel dan tidak harus dalam waktu yang sama, misalkan menggunakan forum diskusi atau belajar mandiri/penugasan mahasiswa.

\section{Pelaksanaan Pembelajaran oleh Dosen Digital Imigrant pada Masa Pandemi}

Pandemi Covid-19 dan keluarnya surat keputusan Rektor Universitas Negeri Padang membuat sistem pembelajaran di Universitas Negeri Padang harus dilaksanakan dengan sistem E-Learning secara penuh. Keadaan ini membuat hampir semua dosen melakukan akses ke ELearning UNP tidak terkecuali dosen dengan kategori digital immigrant. Berdasarkan data 
penelitian didapatkan bahwa sebanyak $84 \%$ dosen digital immigrant menyatakan baru pertama kali membuka E-Learning UNP. Sementara $12 \%$ menyatakan bahwa pernah membuka dan mengakses E-Learning, namun hanya $4 \%$ dosen digital immigrant yang menyatakan pernah memanfaatkan E-Learning untuk kepentingan pembelajaran. Lebih jelas data dapat dilihat pada grafik di bawah ini:

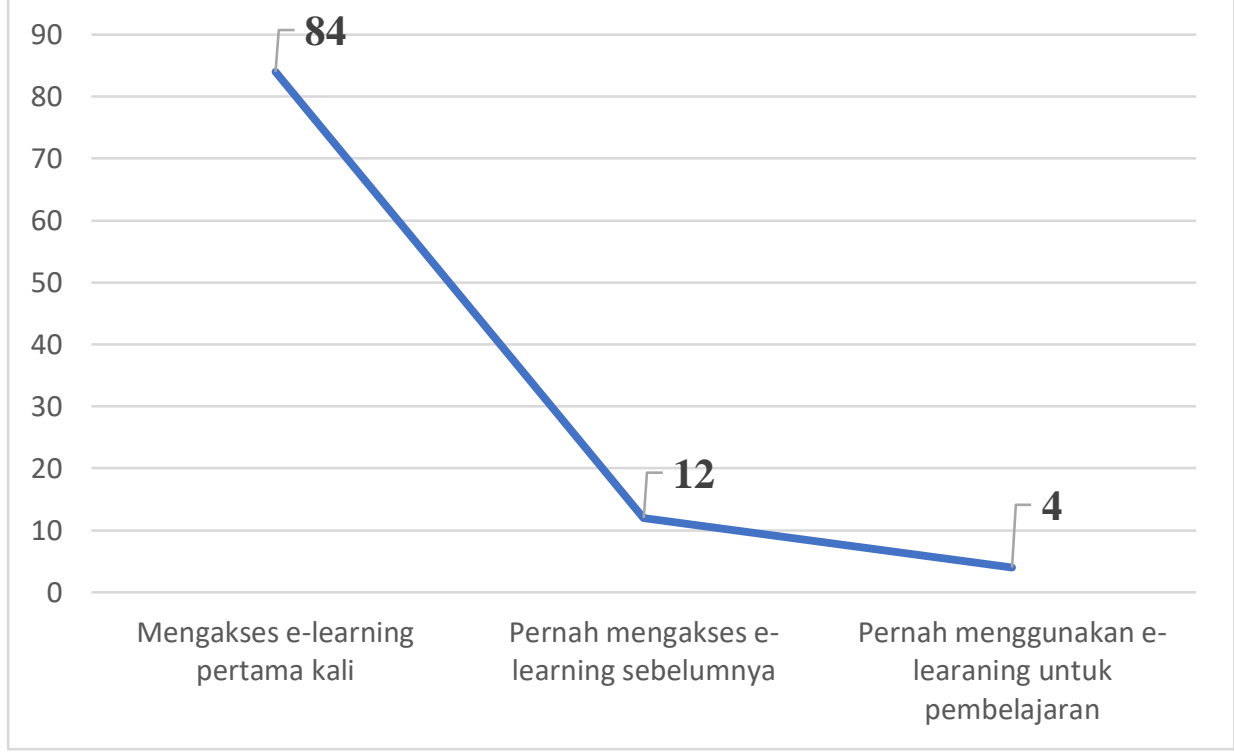

Gambar 1. Pemanfaatan E-Learning Oleh Dosen Digital Immigrant di UNP

Data di atas merupakan identifikasi awal tingkat adaptasi dosen digital immigrant untuk dengan pola pembelajaran baru. Data lebih lanjut berkaitan dengan upaya agar dapat melaksanakan pembelajaran dengan sistem E-Learning. Dosen digital immigrant melakukan upaya sebagai bentuk adaptasi terhadap pembelajaran baru yaitu dengan mengikuti berbagai macam pelatihan pemanfaatan E-Learning UNP ditingkat jurusan dan belajar kepada sejawat atau dosen muda. Data penelitian menunjukkan bahwa $92 \%$ dosen digital immigrant mengaku mengikuti pelatihan pemanfaatan E-Learning yang diadakan oleh jurusan, masing-masing dan hanya $8 \%$ dosen digital immigrant yang tidak mengikuti pelatihan E-Learning oleh jurusan. Lebih dari itu setelah pelatihan penggunaan E-Learning UNP beberapa dosen digital immigrant mempelajari lebih lanjut tentang pemanfaatan E-Learning UNP untuk kepentingan pembelajaran. Adapun langkah yang mereka lakukan adalah belajar dengan sejawat dosen muda dan belajar dengan cara mengakses Youtube tentang tutorial mengajar dengan ELearning.

Mengikuti pelatihan, belajar dengan sejawat dan mempelajari pemanfaatan E-Learning melalui Youtube merupakan upaya adaptasi yang dilakukan oleh dosen digital immigrant agar dapat melaksanakan pembelajaran dengan sistem E-Learning. Namun sangat disayangkan banyak dosen digital immigrant belum bisa memanfaatkan secara maksimal content ELearning setelah melaksanakan pelatihan. Adapun content pada E-Learning yang bisa dibuat oleh dosen digital immigrant baru pada tahapan mengupload bahan ajar. Data menunjukkan hanya $36 \%$ dosen yang bisa membuat dan melaksanakan pembelajaran menggunakan ELearning sementara $64 \%$ menyatakan belum bisa menggunakan E-Learning untuk pembelajaran. Lebih jelas data dapat dilihat pada grafik dibawah ini: 


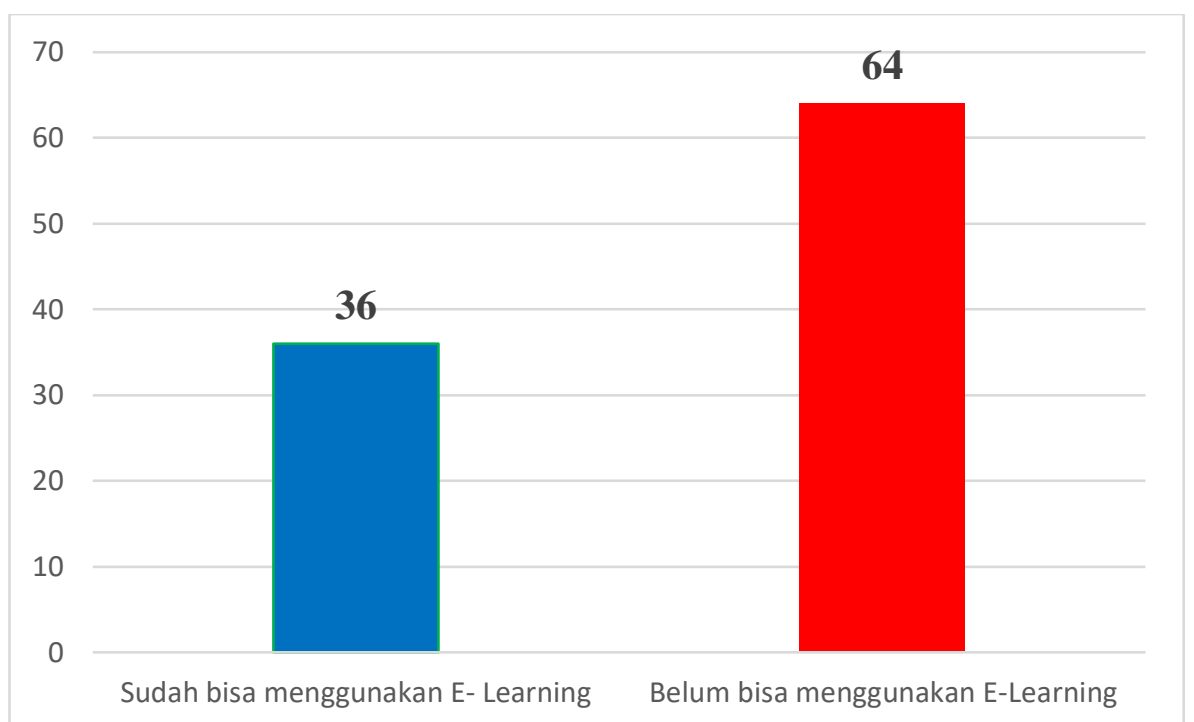

Gambar 2. Kemampuan menggunakan E-Learning dalam pembelajaran

Data diatas menunjukkan bahwa kemampuan Dosen digital immigrant dalam memanfaatkan E-Learning sangat rendah. Lebih lanjut dalam melaksanakan pembelajaran daring selama pandemi Covid-19 dosen digital immigrant di Universitas Negeri Padang yang konsisten memilih menggunakan platform E-Learning UNP hanya 20,7 \% selebihnya memilih mengunakan aplikasi lain yang dapat digunakan untuk kepentingan pembelajaran diantaranya: aplikasi video conference (Google meet, Zoom meeting) $69 \%$, membuat video pembelajaran (Youtube) 1,4 \%, WhatsApp group 5,5\%, dan lainnya 3,4\%.

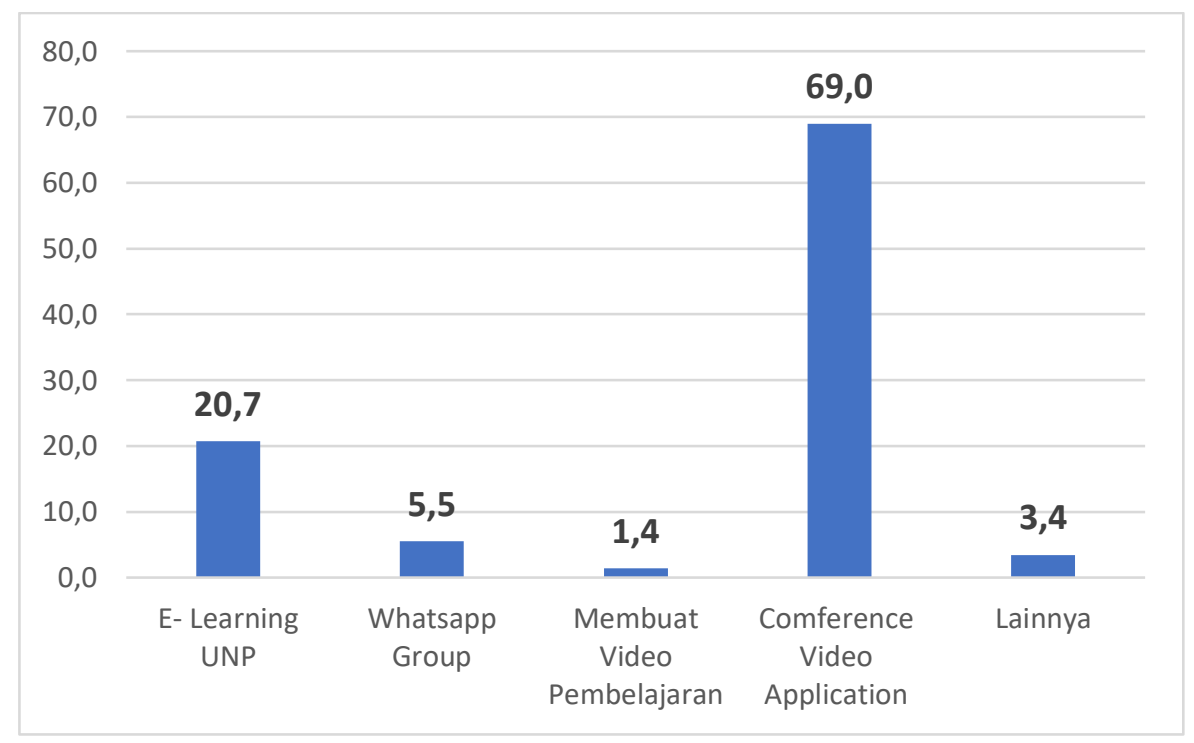

Gambar 3. Aplikasi yang digunakan dalam proses pembelajaran daring

Temuan penelitian di atas menyatakan bahwa pilihan pembelajaran yang dominan dilakukan oleh dosen digital immigrant adalah secara sinkronus melalui video conference sebanyak $69 \%$ dan aplikasi WhatsApp sebanyak 1,4\%. fenomena sejalan dengan pendapat (Reid \& Ostashewski, 2011) yang menyatakan digital immigrant dipandang terlalu sulit untuk mempelajari teknologi baru dan juga sudah terlambat bagi mereka untuk belajar tentang perangkat elektronik baru, program pendidikan elektronik, dan aplikasi. Dosen digital immigrant di UNP sulit mempelajari pembelajaran menggunakan E-Learning yang dipandang rumit namun digital immigrant juga berupaya mempelajari aplikasi alternatif yang bisa digunakan untuk pembelajaran. Hal tersebut sesuai dengan pendapat (Ransdell et al., 2011) 
meskipun dosen digital immigrant kurang percaya diri dalam penggunaan teknologi, mereka mampu menerapkan apa yang mereka pelajari tentang teknologi lebih baik dari pada penduduk asli digital. Selama para dosen digital immigrant memiliki waktu dan aksesibilitas yang cukup, mereka dapat mempelajari teknologi untuk menjadi penduduk asli digital yang sebenarnya.

Data di atas juga menunjukkan meskipun pembelajaran daring dengan sistem E-Learning menawarkan sinkronus dan asinkronus. Namun pilihan menggunakan aplikasi sinkronus lebih diminati oleh dosen digital immigrant. Hal ini disebabkan oleh Karakteristik digital immigrant dalam pembelajaran lebih suka interaksi langsung dari pada interaksi digital. Menurut mereka dalam proses pembelajaran seorang pendidik dapat mengevaluasi pembelajaran melalui komunikasi nonverbal (Bahasa tubuh, nada suara, ekspresi wajah) (Riegel \& Mete, 2017). Penelitian Kinash \& Wood (2013) mengungkapkan digital immigrant lebih melihat teknologi hanya sebagai tambahan memperlancar proses pembelajaran seperti menggunakan video sebagai alat bantu untuk menjelaskan pembelajaran, namun tidak mengganggap mengajar dengan penggunaan teknologi digital sebagai proses pembelajaran.

\section{Adaptasi Digital Immigrant dalam Pembelajaran pada Masa Pandemi Covid-19 (Sebuah Tinjauan Sosiologis)}

Covid-19 telah mengakibatkan pergeseran sistem pembelajaran dari pembelajaran tatap muka menjadi pembelajaran pembelajaran secara daring. Konsekuensi tersebut tidak bisa dihindari. Universitas Negeri Padang juga melakukan hal yang sama. Pembelajaran di Universitas Negeri Padang dilakukan secara daring dengan menggunakan E-Learning UNP. Pada satu sisi perubahan ini merupakan solusi agar proses pembelajaran di perguruan tinggi tetap berjalan. Namun pada sisi lain, pergeseran pola pembelajaran ini mengakibatkan pergeseran pada sub sistem lainnya. Dalam hal ini sub sistem dalam perguruan tinggi yang paling merasakan dampak perubahan tersebut adalah dosen digital immigrant.

Untuk menjawab bagaimana proses adaptasi dosen digital immigrant dalam pembelajaran pada masa pandemic dapat dijelaskan dengan perspektif Teori struktural fungsional yang kemukakan Talcott Parsons sebagai upaya adaptasi. Menurut Talcott Parsons dalam (Ritzer \& Goodman, 2008) struktur sosial dan pranata sosial berada dalam suatu system sosial yang berdiri atas bagian-bagian atau elemen-elemen yang saling berkaitan dan menyatu dalam keseimbangan. Asumsi dalam teori ini menganggap bahwa setiap struktur dalam sistem sosial, fungsional terhadap yang lain, sebaliknya kalau tidak fungsional maka struktur itu tidak akan ada atau hilang dengan sendirinya. Selanjutnya dalam pandangan Parsons sebuah sistem membutuhkan 4 fungsi penting agar tetap berada pada posisi seimbang yaitu: Adaptation (Adaptasi), Goal Attainment (Pencapaian Tujuan), Integration (Integrasi) dan Latency (Pemeliharaan Pola).

Sebagai upaya menjaga proses pembelajaran di Universitas Negeri Padang berjalan dengan baik, dosen digital immigrant melakukan Adaptation. Pada proses ini dosen digital immigrant melakukan penyesuaian diri terhadap sistem pembelajaran baru. Dalam rangka menyesuaikan diri dosen digital immigrant mengikuti berbagai pelatihan, belajar kepada teman sejawat, dan melihat content Youtube toturial menggunakan E-Learning. Berikut kutipan wawancara yang dilakukan dengan dosen digital immigrant:

“...Agar dapat menggunakan E-Learning sebagaimana instruksi dari Rektor UNP, Saya mengikuti berbagai pelatihan yang diadakan oleh Universitas dan Jurusan. Tidak hanya itu saya juga belajar secara khusus kepada dosen-dosen muda yang ada di jurusan (Wawancara, Juni 2020) 
Pernyataan serupa juga dikemukakan oleh narasumber lain:

“...Agar saya bisa menggunakan E-Learning untuk kepentingan pembelajaran saya belajar dengan dosen-dosen muda yang ada di Jurusan. Selain itu saya juga mengikuti akun Youtube yang membahas tutorial penggunaan E-Learning (Wawancara, Juni 2020).

Upaya mengikuti berbagai pelatihan dalam penggunaan E-Learning yang dilakukan oleh dosen digital immigrant belum membuahkan hasil. Dimana masih banyak dosen digital immigrant yang belum bisa melaksanakan pembelajaran dengan E-Learning UNP. Hal tersebut terkonfirmasi dari hasil wawancara sebagai berikut:

“...Meskipun saya sudah ikut pelatihan namun saya juga belum bisa menggunakan ELearning UNP tersebut. Menurut saya E-Learning itu tidak praktis. (Wawancara, Juni 2020).

Narasumber lain juga menuturkan:

“...Sampai saat ini saya belum bisa menggunakan E-Learning terlalu banyak yang harus di isi dalam E-Learning. Sementara saya juga harus mempersiapkan bahan ajar dan media pembelajaran lainnya (Wawancara, Juni 2020).

Keterbatasan dalam menggunakan E-Learning UNP membuat digital immigrant melakukan upaya lain agar tetap bisa mengajar secara daring dan tujuan pembelajaran dapat dicapai (Goal Attainment). Mewujudkan semua itu dosen digital immigrant melakukan Integration dan Pemeliharaan Pola. Pembelajaran yang harusnya menggunakan E-Learning UNP diganti dengan menggunakan platform digital lainnya. Adapun teknologi pembelajaran yang menurut mereka mudah digunakan seperti WhatsApp Group, aplikasi video conference (Google meet, Zoom meeting). Data tersebut terkonfirmasi dari hasil wawancara sebagai berikut:

“...Bagi saya yang penting proses pembelajaran daring ini berjalan dengan baik. Yang penting saya mengirimkan bahan ajar melalui aplikasi WhatsApp dan mengajar menggunakan Zoom meeting (Wawancara, Juli 2020)

Pernyataan yang sama juga dikemukakan oleh narasumber lain yang menyatakan:

“...Yang terpenting dalam pembelajaran online ini saya mengajar dan bertatap muka dengan mahasiswa melalui aplikasi Zoom meeting sementara bahan dapat saya share menggunakan WhatsApp. Saya menganggap E-Learning ini rumit. (Wawancara, Juli 2020)

Terlihat dalam proses ini digital immigrant tampaknya memiliki perspektif dan preferensi mereka sendiri dalam menggunakan platform WhatsApp dan video conference. Bagi mereka, E-Learning UNP adalah platform pembelajaran formal yang tidak sederhana dan tidak praktis digunakan. Sementara aplikasi WhatsApp adalah sesuatu yang sudah biasa digunakan dalam berkomunikasi selama ini bagi digital imigrant. Aplikasi WhatsApp bagi digital imigrant dapat dimanfaatkan untuk memulai membuka wacara diskusi atau hanya sekedar mengirimkan pedoman tugas untuk kepentingan pembelajaran. Melalui pembelajaran menggunakan WhatsApp, mereka memiliki kebebasan untuk memilih dan mengembangkan hubungan dengan mahasiswa mereka secara virtual dan menciptakan komunitas pembelajaran dan berbagi yang dipersonalisasi (Tung 2012). Hicks and Graber (2010) mengklaim bahwa percakapan peserta didik tentang pembelajaran jejaring sosial dapat membantu mereka mengatasi rasa kesepian dan juga mengembangkan rasa kontrol diri mereka selama proses belajar mereka. Ini dapat ditunjukkan oleh beberapa umpan balik para imigran digital yang menyatakan bahwa pesan dalam kelompok bermanfaat dan membuat mereka lebih sadar akan tugas mereka serta perkembangan pembelajaran mereka. Namun, Tung (2012) menunjukkan 
bahwa peserta didik cenderung berfokus pada orang-orang daripada hanya konten pembelajaran.

Sementara pilihan penggunaan aplikasi seperti video conference (Google Meet, Zoom Meeting) memang didasari oleh karakteristik digital immigrant dalam pembelajaran lebih suka interaksi langsung (sinkronus) dari pada interaksi secara tidak langsung (asinkronus) (Riegel \& Mete, 2017). Menurut mereka dalam proses pembelajaran seorang pendidik dapat mengevaluasi pembelajaran melalui komunikasi non-verbal (Bahasa tubuh, nada suara, ekspresi wajah). Penelitian Kinash \& Wood (2013) juga mengungkapkan digital immigrant lebih melihat teknologi hanya sebagai tambahan memperlancar proses pembelajaran seperti menggunakan video sebagai alat bantu untuk menjelaskan pembelajaran, namun tidak menganggap mengajar dengan asinkronus sebagai proses pembelajaran. dalam pembelajaran selama ini digital immigrant lebih memilih menggunakan metode ceramah dalam mengajar (Chng, 2020). Mereka menganggap metode ceramah merupakan cara yang tepat untuk melakukan transfer ilmu pengetahuan kepada siswa (Maudiarti, 2018). Berikut penuturan wawancara dengan narasumber:

“...Menurut saya mengajar itu ya harus bertatap muka dengan mahasiswa. Dalam pembelajaran online ini untung ada aplikasi Zoom meeting sehingga saya dalam mengajar bisa bertatap muka dengan mahasiswa. (Wawancara, Juli 2020)"

Sementara narasumber lain mengatakan

“...Saya bersyukur ada aplikasi Zoom meeting, setelah saya tau ada aplikasi itu saya mempelajarinya, ternyata aplikasi ini cukup mudah menggunakannya. Dengan aplikasi ini saya merasakan Kembali bertemu dengan mahasiswa dan menjelaskan tentang materi kuliah saya secara langsung (Wawancara, Juli 2020)

Pilihan aplikasi yang digunakan oleh digital immigrant dalam pembelajaran daring memiliki konsekuensi terhadap bentuk pembelajaran yang dilaksanakan. Dalam artian aplikasi video conference (Google Meet, Zoom Meeting) dan WhatsApp merupakan aplikasi yang dapat menunjang pembelajaran secara sinkronus. Sementara pada sisi lain berdasarkan surat edaran rektor UNP Nomor 258/UN35/EP/2020 tentang Pelaksanaan perkuliahan dan sistem kerja pada semester Juli-Desember 2020 menyatakan dengan tegas bahwa dosen dalam melaksanakan perkuliahan wajib menggunakan platform www.elearning2.unp.ac.id . Sementara penggunaan aplikasi digital lainnya seperti Google Meet, Zoom Meeting dan aplikasi sejenisnya tetap diperbolehkan jika sangat dibutuhkan. Artinya edaran rektor tersebut lebih menyarankan pembelajaran lebih banyak dilakukan secara asinkronus. Namun pilihan digital immigrant karena keterbatasan dan karakter yang mereka miliki membuat pembelajaran sinkronus menjadi pilihan utama meskipun teknologi yang menunjang untuk melaksanakannya juga baru dipelajarinya.

Kebijakan UNP melaksanakan perkuliahan menggunakan platform E-Learning sendiri diikuti dengan sistem evaluasi yang ketat. Penjamin Mutu Internal baik ditingkat Universitas, Fakultas dan Jurusan akan bekerja selama periodik E-Learning masing-masing dosen. Adapun evaluasi yang dilakukan berkaitan ketersediaan konten E-Learning seperti: ketersediaan Rencana Pembelajaran Semester, kesesuaian minggu perkuliahan dengan jadwal, Absensi, bahan ajar, kuis, tugas, forum diskusi, penilaian. Untuk menyiasati pemenuhan administrasi di E-Learning tersebut dosen digital immigrant meminta bantuan kepada sejawat dosen muda untuk menginputkan konten-konten tersebut ke dalam E-Learning nya. Meskipun secara prinsip kebutuhan dalam pelaksanaan pembelajaran seperti rencana pembelajaran semester, bahan ajar, media pembelajaran, soal ujian, bahan tugas dibuat dan disediakan oleh digital immigrant. Berikut kutipan wawancaranya: 
“...Jadi E-Learning ini harus di isi sementara kami masih belum bisa menggunakannya. Akhirnya yang kami lakukan adalah meminta bantuan kepada dosen muda untuk mengisi E-Learning tersebut. Sementara kami tetap mempersiapkan bahan ajar dan segala sesuatu yang menunjang pembelajaran (Wawancara, Juli 2020)"

Pernyataan senada juga dikemukakan oleh narasumber lain:

“...Saya mengajar menggunakan aplikasi Google Meet untuk keperluan administrasi di E-Learning saya meminta adik-adik dosen muda yang mengisi E-Learning tersebut untuk kepentingan upload tugas, absen dan kuis (Wawancara, Juli 2020)

Berdasarkan temuan diatas terlihat Dosen digital immigrant memiliki keterbatasan dalam menggunakan E-Learning untuk kepentingan pembelajaran. Adaptasi yang mereka lakukan agar tujuan pembelajaran tercapai dalam pembelajaran daring adalah dengan berpartisipasi dalam berbagai macam pelatihan terkait pemanfaatan E-Learning, mengajar dengan menggunakan aplikasi belajar lainnya seperti WhatsApp, Google meet dan Zoom Meeting. Sementara agar secara administrasi tercatat dalam sistem E-Learning dosen digital immigrant meminta bantuan kepada dosen yang memiliki usia muda untuk menginputkan bahan-bahan untuk kepentingan pembelajaran ke dalam E-Learning UNP.

\section{Simpulan}

Berdasarkan penelitian di atas maka penelitian ini dapat disimpulkan bahwa pandemi Covid-19 telah membawa perubahan pada sistem pembelajaran di perguruan tinggi dari pembelajaran tatap muka langsung menjadi pembelajaran secara daring berbasis teknologi digital. Menyikapi hal tersebut Universitas Negeri Padang mengeluarkan kebijakan pembelajaran di kampus dilaksanakan menggunakan platform E-Learning UNP. Kebijakan tersebut cukup sulit bagi dosen dengan kategori digital immigrant untuk mengikuti dan melaksanakannya. Bagi dosen digital immigrant sistem E-Learning UNP tersebut platform pembelajaran formal yang tidak sederhana dan tidak praktis digunakan. Meskipun demikian dosen digital immigrant tetap beradaptasi dengan sistem pembelajaran secara daring ini. Adapun langkah yang dilakukannya terus belajar memanfaatkan platform E-Learning UNP untuk pembelajaran sembari melaksanakan pembelajaran secara sinkronus menggunakan aplikasi digital lainnya seperti WhatsApp dan aplikasi video conference (Google Meet dan Zoom Meeting). Sementara untuk pemenuhan administrasi di E-Learning tersebut dosen digital immigrant meminta bantuan kepada sejawat dosen muda untuk menginputkan konten-konten tersebut ke dalam E-Learning nya. Namun secara prinsip, kebutuhan dalam pelaksanaan pembelajaran seperti rencana pembelajaran semester, bahan ajar, media pembelajaran, soal ujian, bahan tugas tetap dirancang dan disediakan oleh digital immigrant. Hal ini dilakukannya demi menjaga proses pembelajaran tetap berlangsung di masa pandemi Covid-19.

\section{Rujukan}

Andrizal, A., \& Arif, A. (2017). Pengembangan Media Pembelajaran Interaktif Pada Sistem ELearning Universitas Negeri Padang. INVOTEK: Jurnal Inovasi Vokasional Dan Teknologi, 17(2), 1-10. https://doi.org/10.24036/invotek.v17i2.75

Bentri, A., \& Rahmi, U. (2016). Blended Learning System di LPTK: Mempersiapkan Tenaga Pendidik dan Kependidikan yang Berkualitas.

Bowe, B. J., \& Wohn, D. Y. (2015). Are There Generational Differences? Social Media Use and Perceived Shared Reality. ACM International Conference Proceeding Series, 2015 July(July). https://doi.org/10.1145/2789187.2789200 
Chng, L. K. (2020). Face-to-Face Tutorials, Learning Management System and WhatsApp Group: How Digital Immigrants Interact and Engage in E-learning? Malaysian Online Journal of Educational Technology, 8(1), 18-35.

Creswell, J. (2013). Qualitative, quantitative, and mixed methods approaches. SAGE Publication

Ghaith, G. (2010). An exploratory study of the achievement of the twenty-first century skills in higher education. Education and Training, 52(6), 489-498.

Helsper, E. J., \& Eynon, R. (2010). Digital natives: Where is the evidence? British Educational Research Journal, 36(3), 503-520.

Horton, W. (2011). E-learning by design. John Wiley \& Sons.

Kennedy, G. E., Judd, T. S., Churchward, A., Gray, K., \& Krause, K. L. (2008). First year students' experiences with technology: Are they really digital natives? Australasian Journal of Educational Technology, 24(1), 108-122. https://doi.org/10.14742/ajet.1233

Khairudin, K., Rahmi, E., Rahmidani, R., Rusdinal, R., \& Gistituati, N. (2019). Analisis Kebijakan Penggunaan E-Learning Di Universitas Negeri Padang. Jurnal Ilmu Sosial Dan Humaniora, 8(2), 97. https://doi.org/10.23887/jish-undiksha.v8i2.21375

Kinash, S., \& Wood, K. (2013). Academic developer identity: How we know who we are. International Journal for Academic Development, 18(2), 178-189. https://doi.org/10.1080/1360144X.2011.631741

Komariah, A., Kurniady, D. A., \& Rusdinal. (2019). The relationship between the role of a principal and quality of school academic service: The mediating function of teacher commitment. International Journal of Innovation, Creativity and Change, 9(3), 19-34.

Koumachi, B. (2019). "Digital Natives" Mythbusted The Digital Turn in Higher Education: "Digital Natives" Mythbusted. International Journal of Technology in Education and Science (IJTES), 3(1), 56-62.

Li, Y., Wang, Q., \& Lei, J. (2020). Exploring Technology Professional Development Needs of Digital Immigrant Teachers and Digital Native Teachers in China. International Journal of Information and Communication Technology Education, 16(3), 15-29. https://doi.org/10.4018/ijicte.2020070102

Maudiarti, S. (2018). Penerapan E-Learning Di Perguruan Tinggi. Perspektif Ilmu Pendidikan, 32(1), 51-66. https://doi.org/10.21009/pip.321.7

Mayes, T., \& De Freitas, S. (2007). Learning and e-learning. Rethinking Pedagogy for a Digital Age, 13-25.

O'Bannon, B. W., \& Thomas, K. (2014). Teacher perceptions of using mobile phones in the classroom: Age matters! Computers and Education, 74(1), 15-25. https://doi.org/10.1016/j.compedu.2014.01.006

Prensky, M. (2001a). Digital Native, Digital Immigrant Part 1. On the Horizon, 9(5), 1-6.

Prensky, M. (2001b). Digital Natives, Digital Immigrants. MCB University Press, 9(5), 1-6.

Rahmat, I., \& Ridwan, R. (2020). Implementasi Andragogi Platform E-learning pada Blended Learning di Universitas Negeri Padang. Journal of Education Technology, 4(2), 133140.

Ransdell, S., Kent, B., Gaillard-Kenney, S., \& Long, J. (2011). Digital immigrants fare better than digital natives due to social reliance. British Journal of Educational Technology, 42(6), 931-938. https://doi.org/10.1111/j.1467-8535.2010.01137.x 
Reid, D., \& Ostashewski, N. (2011). iPads in the Classroom-New Technologies, Old Issues: Are they worth the effort? World Conference on Educational Multimedia Hypermedia and Telecommunications 2011, 2011, 1689-1694.

Riegel, C., \& Mete, R. (2017). Educational Technologies for K-12 Learners: What Digital Natives and Digital Immigrants Can Teach One Another. Educational Planning, 24(4), 49-58.

Ritzer, G., \& Goodman, D. J. (2008). Teori Sosiologi Modern Edisi Keenam. Jakarta: Kencana.

Rusli, R., Rahman, A., \& Abdullah, H. (2020). Student perception data on online learning using heutagogy approach in the Faculty of Mathematics and Natural Sciences of Universitas Negeri Makassar, Indonesia. Data in Brief, 29, 105152. https://doi.org/10.1016/j.dib.2020.105152

Salajan, F. D., Schönwetter, D. J., \& Cleghorn, B. M. (2010). Student and faculty intergenerational digital divide: Fact or fiction? Computers and Education, 55(3), 1393-1403. https://doi.org/10.1016/j.compedu.2010.06.017

Teo, T. (2016). Do digital natives differ by computer self-efficacy and experience? An empirical study. Interactive Learning Environments, 24(7), 1725-1739. https://doi.org/10.1080/10494820.2015.1041408

Thinyane, H. (2010). Are digital natives a world-wide phenomenon? An investigation into South African first year students' use and experience with technology. Computers and Education, 55(1), 406-414. https://doi.org/10.1016/j.compedu.2010.02.005

Thomas, K., \& O'Bannon, B. W. (2015). Looking Across the New Digital Divide: A Comparison of Inservice and Preservice Teacher Perceptions of Mobile Phone Integration. Journal of Technology and Teacher Education, 23(4), 561-581.

UNESCO. (2020). Startling digital divides in distance learning emerge.

Viner, R. M., Russell, S. J., Croker, H., Packer, J., Ward, J., Stansfield, C. (2020). School closure and management practices during coronavirus outbreaks including COVID-19: a rapid systematic review. The Lancet Child \& Adolescent Health, O(0), 397-404. https://doi.org/10.1016/S2352-4642(20)30095-X 